\title{
Perkiraan Pemakaian dan Kebutuhan Beban Energi Listrik Rayon Juwana Menggunakan Jaringan Saraf Tiruan (Radial Basis Function)
}

\author{
Moh Tamam Edy Fitriyan ${ }^{1)}$, Sri Heranurweni ${ }^{2)}$, Harmini ${ }^{3)}$ \\ 1,2),3) Jurusan Teknik Elektro, Fakultas Teknik, Universitas Semarang \\ 1,2), 3) Jl. Soekarno Hatta, Tlogosari Kulon, Kec. Pedurungan, Kota Semarang, Jawa Tengah 59160 \\ e-mail: tamamseven@gmail.com ${ }^{1)}$, heranur@usm.ac.id ${ }^{2)}$, harmini@usm.ac.id ${ }^{3)}$
}

\begin{abstract}
Along with the development of the times the need for electrical energy is increasing. PT. PLN (Persero) as a company that supplies electrical energy must be able to meet the needs of electrical energy to run a business to supply electric power in an even amount to meet the needs of the household, industrial, social and business sectors.. The purpose of this research to determine how much the growth of electrical loads in 2020 to 2025 at PT. PLN (Persero) Rayon Juwana. To find out the amount of increase in electrical energy required. Electrical data used data for 8 years, from 2012 to 2019. The results of this study are in the form of an estimate of the use and need for load electrical energy load for the next 5 years, from 2020 to 2025 , the data used are the number of subscribers, connected power, and the amount of energy using a simulated neural network with the method (radial basis function). the results of this study an increase per year an average of $1 \%$ per year. in 2019 the value is $1.07 \%$, in 2020 it is 1.10\%, 2021 is 1.21\%, for 2022 it is 1.27\%, 2023 is $1.28 \%$, 2024 is $1.17 \%$ and 2025 is $1.31 \%$.
\end{abstract}

Keywords: peak load, load forecasting, artificial neural networks, radial basis function.

\begin{abstract}
ABSTRAK
Kebutuhan energi listrik tiap tahun semakin meningkat, sehingga PT. PLN (Persero) sebagai perusahaan yang mensuplai energi listrik harus mampu untuk memenuhi kebutuhan energi listrik dan penyediaan daya listrik dalam jumlah merata dalam memenuhi masyarakat. Penelitian ini bertujuan untuk mengetahui seberapa besar pertumbuhan beban listrik pada tahun 2020 sampai tahun 2025 di PT. PLN(Persero) rayon Juwana Pati. Untuk mengetahui besaran kenaikan energi listrik yang dibutuhkan. Data kelistrikan yang dipakai data selama 8 tahun yaitu dari tahun 2012sampai tahun 2019. Hasil pada penelitian ini berupa perkiraan pemakaian dan kebutuhan beban energi listrik beban untuk 5 tahun ke depan yaitu dari tahun 2020 sampai 2025, data yang digunakan adalah jumlah pelanggan, daya tersambung, dan jumlah energi menggunakan simulasi jaringan saraf tiruan dengan metode (radial basis function), hasil penelitian ini kenaikan pertahun rata-rata 1\% tiap tahunnya. Pada tahun 2019 bernilai 1,07\%, tahun 2020 bernilai 1,10\%, 2021 bernilai 1,21\%, untuk tahun 2022 bernilai 1.27\%, 2023 bernilai 1,28\%, 2024 bernilai $1,17 \%$ dan 2025 bernilai $1,31 \%$.
\end{abstract}

Kata kunci : Beban puncak, Peramalan beban, Jaringan saraf tiruan, radial basis function

\section{Pendahuluan}

$\mathrm{S}$ emakin berkembangnya IPTEK (ilmu pengetahuan dan teknologi) pada zaman serba modern, khususnya pada bidang kelistrikan PT. PLN (Persero) sebagai perusahaan yang mensuplai energi listrik harus mampu untuk memenuhi kebutuhan energi listrik untuk menyelenggarakan usaha penyediaan daya listrik dalam jumlah merata, dimana energi listrik menjadi kebutuhan primer bagi masyarakat seperti dibidang industri, perkantoran, pendidikan, transportasi, rumah tangga sehingga dapat dipastikan kebutuhan energi listrik akan meningkat pada masa yang akan datang. Perkiraan permintaan beban energi listrik berdasarkan jangka waktu di kelompokan menjadi:

1. Perkiraan jangka panjang yaitu permintaan beban listrik dengan waktu diatas 1 (satu) tahun.

2. Perkiraan jangka menengah yaitu permintaan beban listrik dengan waktu beberapa bulan sampai 1 (satu) tahun.

3. Perkiraan jangka pendek yaitu permintaanbeban listrik dengan waktu beberapa jam dalam satu hari sampai dengan satu minggu.[4]
Penelitian ini menggunakan metode jaringan syaraf tiruan Radial BasisFunction, hal ini untuk memprediksi kebutuhan energi listrik sesuai dengan kebutuhan konsumen listrik selama 5 tahun kedepan dari tahun 2020 -2025. Data yang digunakan pada penelitian ini dari ULP Rayon Juwana Pati.

\section{TEORI}

\subsection{Pengelompokan Konsumsi Energi Listrik}

Pembagian pengelompokan konsumsi energi listrik merupakan salah satu hal yang harus diperhatikan demi optimasi dalam perencanaan atau pengadaan sistem tenaga listrik. Pengelompokan konsumsi energi listrik menurut PT.PLN berdasarkandari kelompok pelanggan listrik yang terdiri dari 4 (empat) sektor, yaitu:
1) Sektor Rumah Tangga
2) Sektor Bisnis
3) Sektor Industri
4) Sektor Publik

\subsection{Peramalan Beban Energi Listrik}

Peramalan energi listrik sangat diperlukan untuk memperkirakan kebutuhan energi listrik beberapa tahun kedepan. Peramalan pada dasarnya merupakan suatu 
dugaan atau perkiraan mengenai suatu kejadian atau peristiwa dimasa yang akan datang. pembuatan ramalan kebutuhan tenaga listrik dapat dibagi dalam tiga tahap, yaitu:
a)Pengumpulan dan penyiapan data
b) Pengolahan dan analisa data
c) Penentuan metoda dan pembuatan model

Load Forecasting atau peramalan beban harusdilakukan per UPJ dan total APJ untuk mendapatkangambaran atau prediksi kebutuhan energi listrik.

\subsection{Pengertian Radial Basis Function}

$\operatorname{RBF}(\varphi)$ merupakan fungsi dimana keluarannya simetris terhadap center $\mathrm{c}$ tertentu atau dinyatakan sebagai $\varphi c=\varphi\|x-c\|$, dimana $\|$.$\| merupakan vektor$ normal. Jaringan syaraf yang dibentuk dengan menggunakan fungsi basis berupa fungsi basis radialdinamakan Jaringan Syaraf RBF.

Jaringan RBF terdiri atas 3 layer yaitu input layer, hidden layer (unit tersembunyi) dan output layer. Masing-masing unit tersembunyi merupakan fungsi aktifasi yang berupa fungsi basis radial. Fungsi basis radial ini diasosiasikan oleh lebardan posisi center dari fungsi basis tersebut. Struktur dasar jaringan RBF dapat dilihat pada Gambar 1.[3]

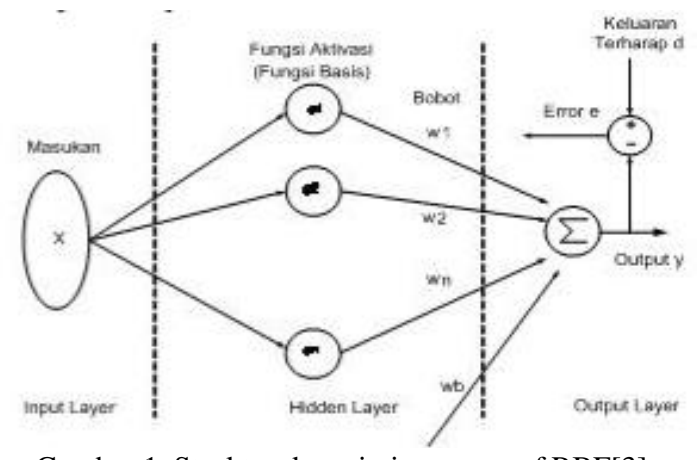

Gambar 1. Struktur dasar jaringan syaraf RBF[3]

Setiap input dari jaringan syaraf tiruan RBF ini akanmengaktifkan semua fungsi basis pada hidden layer. Setiap unit dari hidden layer merupakan fungsi aktivasi tertentu yang disebut sebagai fungsi basis. Di dalam hidden layer terdapat sejumlah fungsi basis yang sejenis. Setiap fungsi basis akan menghasilkan sebuah keluaran dengan bobot tertentu.

\subsection{Algoritma Pelatihan RBF}

Algoritma pelatihan RBF secara iteratif memilikilangkah - langkah sebagai berikut:

Langkah 1: Menentukan jumlah fungsi basis yang akan digunakan.

Langkah 2: Menentukan center tiap fungsi basis.

Langkah 3: Menyediakan bobot sebanyak (fungsi basis) $n+1$, dimana $n$ adalah jumlahmasukan jaringan syaraf tiruan RBF.

Langkah 4: Inisialisasi bobot $\mathrm{w}=\left[\begin{array}{lll}0 & 0 & 0 \ldots . .0\end{array}\right]$, masukan laju konvergensi yang digunakan $(0<\alpha<1)$.

Langkah 5: Untuk setiap sinyal latih kerjakan langkah 6 - selesai.

Langkah 6: Hitung keluaran tiap fungsi b sis.

Langkah 7: Hitung keluaran jaringan RBF.

Langkah 8: Hitung kesalahan (error) antara sinyal terharap (d) dengan keluaran RBF y error $=\mathrm{d}-\mathrm{y}$.

Langkah 9: Update bobot-bobot tiap fungsi basis danbobot basis dengan metoda LMS.[6]

\section{METODE}

Pada penelitian ini menjelaskan tentang peramalan beban puncak energi listrik. Secara keseluruhan dapat dilihat dalam Flowchart berikut:

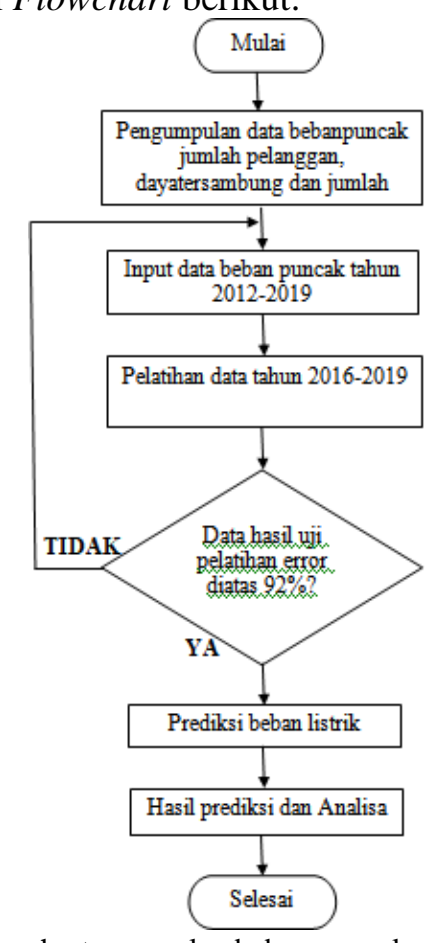

Gambar 2. Flowchart peramalan beban puncak energi listrik

\subsection{Pengambilan Data}

Kegiatan yang bertujuan untuk mendapatkan dan melengkapi data yang diperlukan untuk melakukan penelitian. Data-data yang diperlukan untuk menyusun laporan tugas akhir diperoleh dari instansi terkait yaitu PLN ULP Juwana Pati ataupun sumber lain. Data yang diambil dari PLN berupa data historis laporan penjualan energi listrik meliputi jumlah pelanggan, daya tersambung (VA) dan jumlahenergi (kWh). Data tersebut merupakan penjualan dari tahuntahun sebelumnya yaitu tahun 2012 sampai tahun 2019 atau delapan tahun terakhir untuk meramal beban puncak listrik kedepan dari tahun 2020 sampai tahun 2025 . 


\subsection{Pengolahan Data}

Sebelum data dimasukan pada jaringan Syaraf Tiruan maka harus di ubah kedalam bilangandesimal atau dinormalisasi dalam range 0 sampai dengan 0,9 karena data masukan Jaringan Syaraf Tiruan menggunakan fungsi aktivasi logsig (sigmoidbiner). Sebelum data dirubah kedalam bentukbilangan desimal, lebih baik data di kecilkan nilainya agar sistem membaca dengan baik.

\subsection{Data Kelistrikan}

Data ini diperoleh dari dari instansi bersangkutan yaitu PT. PLN ULP Juwana Pati, berupa jumlah pelanggan, daya tersambung (VA), dan jumlah energi $(\mathrm{kWh})$ pada tiap sektor.

a) Jumlah pelanggan

Data jumlah pelanggan PT. PLN ULP Juwana Pati dari tahun 2012 - 2019 yang diperoleh seperti tabel 1. berikut :

Tabel 1. Data Jumlah Pelanggan

\begin{tabular}{|c|r|r|r|r|}
\hline TAHUN & $\begin{array}{c}\text { RUMAH } \\
\text { TANGGA }\end{array}$ & INDUSTRI & BISNIS & PUBLIK \\
\hline 2012 & 12656 & 930 & 4074 & 3478 \\
\hline 2013 & 13356 & 1250 & 4284 & 3675 \\
\hline 2014 & 13852 & 1410 & 4640 & 3818 \\
\hline 2015 & 14368 & 1500 & 5045 & 3984 \\
\hline 2016 & 14706 & 1540 & 5510 & 4191 \\
\hline 2017 & 15251 & 1650 & 6063 & 4411 \\
\hline 2018 & 15863 & 1740 & 6366 & 4623 \\
\hline 2019 & 16229 & 1750 & 6611 & 4770 \\
\hline
\end{tabular}

b) Jumlah Energi

Data jumlah energi pada PT. PLN ULP Juwana Pati dari tahun 2012 - 2019 yang diperoleh seperti tabel 2. berikut :

Tabel 2. Data Jumlah Energi

\begin{tabular}{|c|c|c|c|c|}
\hline Tahun & $\begin{array}{c}\text { Rumah } \\
\text { Tangga } \\
(\mathrm{KWh})\end{array}$ & $\begin{array}{c}\text { Industri } \\
(\mathrm{KWh})\end{array}$ & $\begin{array}{c}\text { Bisnis } \\
(\mathrm{KWh})\end{array}$ & $\begin{array}{c}\text { Publik } \\
(\mathrm{KWh})\end{array}$ \\
\hline 2012 & 11182891 & 1826449 & 1245778 & 709310 \\
\hline 2013 & 11871774 & 2279363 & 1304615 & 729039 \\
\hline 2014 & 12343351 & 2542231 & 1566597 & 779736 \\
\hline 2015 & 13496949 & 2836367 & 1708157 & 857778 \\
\hline 2016 & 14472939 & 2993966 & 1963972 & 961252 \\
\hline 2017 & 14589867 & 3140967 & 2143598 & 1048243 \\
\hline 2018 & 15522942 & 3778029 & 2509549 & 1154410 \\
\hline 2019 & 16561793 & 3787541 & 2941139 & 1299016 \\
\hline
\end{tabular}

c) Daya Tersambung

Data jumlah data tersambung pada PT. PLN

ULP Juwana Pati dari tahun 2012 - 2019 yang diperoleh seperti tabel 3. berikut:

Tabel 3. Data Jumlah Daya Tersambung

\begin{tabular}{|c|c|c|c|c|}
\hline TAHUN & $\begin{array}{c}\text { RUMAH } \\
\text { TANGA } \\
\text { (VA) }\end{array}$ & $\begin{array}{c}\text { INDUSTRI } \\
\text { (VA) }\end{array}$ & $\begin{array}{c}\text { BISNIS } \\
\text { (VA) }\end{array}$ & $\begin{array}{c}\text { PUBLIK } \\
\text { (VA) }\end{array}$ \\
\hline 2012 & 69693,6 & 46862,5 & 46248,5 & 42610,7 \\
\hline 2013 & 74024,8 & 66269,5 & 51336 & 46053,2 \\
\hline 2014 & 77141,5 & 79258 & 65674,5 & 52417,7 \\
\hline 2015 & 81169,5 & 89737 & 73016,3 & 63561,2 \\
\hline 2016 & 94925 & 96417 & 82189 & 78662,3 \\
\hline 2017 & 109289 & 110815 & 95624,5 & 95450,5 \\
\hline 2018 & 123938 & 120302 & 110812 & 111140 \\
\hline 2019 & 137573 & 122727 & 122708 & 126430 \\
\hline
\end{tabular}

\section{HASIL DAN PEMBAHASAN}

\subsection{Metode Pengolahan Data}

\subsubsection{Analisa Jumlah Pelanggan Listrik}

Pada pelatihan pelanggan listrik menggunakan metode jaringan syaraf tiruan radial basis function ke dalam software Matlab yang dilatih dari tahun 2012 sampai tahun 2019.

Tabel 4. Pelanggan Listrik Tahun 2012-2019

\begin{tabular}{|c|r|r|r|r|}
\hline TAHUN & $\begin{array}{c}\text { RUMAH } \\
\text { TANGGA }\end{array}$ & INDUSTR & BISNIS & PUBLIK \\
\hline 2012 & 12656 & 930 & 4074 & 3478 \\
\hline 2013 & 13356 & 1250 & 4284 & 3675 \\
\hline 2014 & 13852 & 1410 & 4640 & 3818 \\
\hline 2015 & 14368 & 1500 & 5045 & 3984 \\
\hline 2016 & 14706 & 1540 & 5510 & 4191 \\
\hline 2017 & 15251 & 1650 & 6063 & 4411 \\
\hline 2018 & 15863 & 1740 & 6366 & 4623 \\
\hline 2019 & 16229 & 1750 & 6611 & 4770 \\
\hline
\end{tabular}

Jaringan Saraf tiruan radial basis function kemudian dilakukan pelatihan dengan data latih pada tabel 5, Parameter ini berdasarkan beberapa kali percobaan dengan merubah beberapa item seperti MSE (target performa), Spread konstant, Jumlah maksimal neuron, Jumlah neuron dibelakang layar untuk mendapatkan nilai eror terkecil, Sehingga Pelatihan menggunakan parameter pada tabel 5 .

Tabel 5. Parameter JST Radial Basis Function

\begin{tabular}{|l|c|}
\hline MSE (Target Performa) & $1 \mathrm{e}-5$ \\
\hline Spread constant & 6 \\
\hline Jumlah maksimal neuron & 80 \\
\hline Jumlah neuron & 100 \\
\hline Fungsi parameter pelatihan & Traingdx \\
\hline Epoch/lerasi & 1000 \\
\hline Gradient & 0,0954 \\
\hline
\end{tabular}

Setelah menggunakan parameter pada tabel 5 , jaringan saraf tiruan radial basis function menggunakan software MATLAB pada perintah M-File yang kemudian membentuk suatu pelatihan dan sistem uji seperti gambar 3. Hasil pengujian dari tahun 2016 sampai 2019, untuk kemudian dilakukan pengujian tingkat eror dari data asli sehingga diketahui tingkat 
keakuratan dari pelatihan jaringan saraf tiruan radial basis function menggunakan Matlab seperti pada tabel 5.

Tabel 5. Perbandingan Data Asli Dengan Data Hasil Uji Prediksi

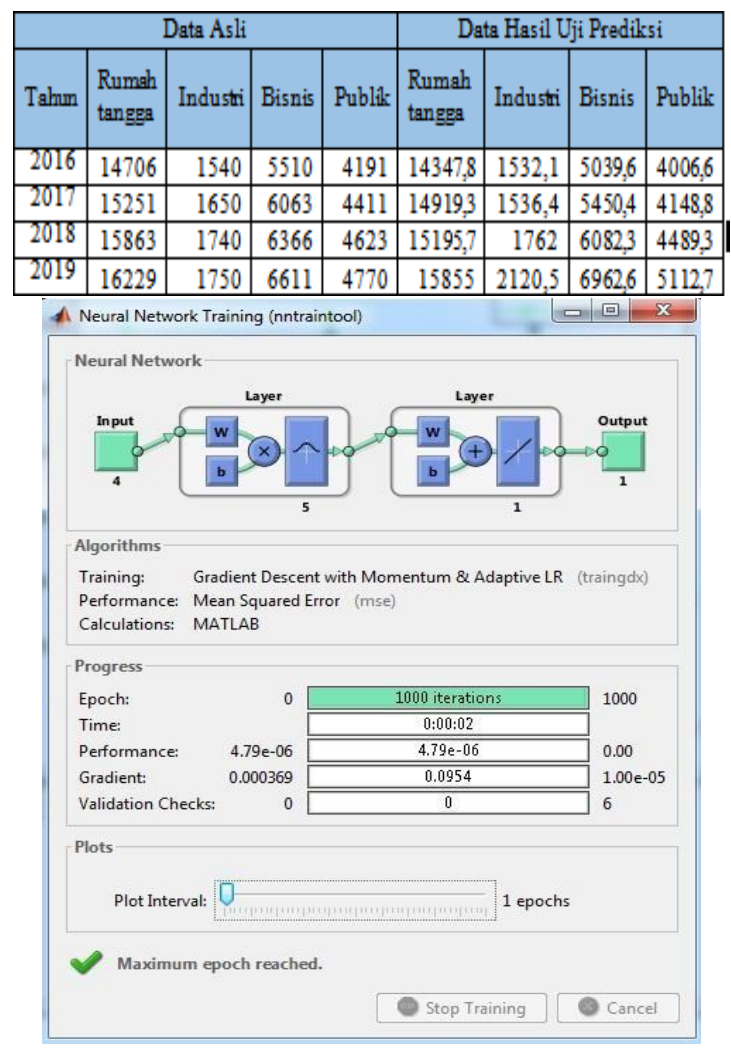

Gambar 3. Hasil Pelatihan Pelanggan

Tabel 5. menunjukkan perbandingan hasil data asli dengan data hasil pengujian dari pelatihan jaringan saraf tiruan radial basis function, kemudian dilakukan perhitungan tingkat eror dengan rumusberikut:

Tingkat akurasi $(\%)=\underline{\text { data uji prediksi }} \times 100$ data asli

Tabel 6. Tingkat Keakuratan Hasil Uji Prediksi

\begin{tabular}{|r|r|r|r|r|r|}
\hline & \multicolumn{3}{|c|}{ TINGKAT AKURASI (\%) } & \multirow{2}{*}{$\begin{array}{c}\text { RATA- } \\
\text { RATA }\end{array}$} \\
\hline TAHUN & $\begin{array}{r}\text { RUMAH } \\
\text { TANGGA }\end{array}$ & INDUSTRI & BISNIS & PUBLIK & \\
\hline 2016 & 97,56 & 99,48 & 91,46 & 95,60 & 96,02 \\
\hline 2017 & 97,82 & 93,11 & 89,89 & 94,05 & 93,72 \\
\hline 2018 & 95,79 & 98,75 & 95,54 & 97,10 & 96,79 \\
\hline 2019 & 97,69 & 82,52 & 94,95 & 93,29 & 92,11 \\
\hline
\end{tabular}

Dari tabel 6. diketahui tingkat akurasi hasil uji prediksi dari tahun 2016 sampai tahun 2019 menunjukkan hasil $92 \%$ keatas, tingkat akurasi tersebut dalam jaringan saraf tiruan dinilai sudahbaik dan bisa untuk dilakukan perkiraan dari tahun 2020 sampai 2025.

Setelah melakukan pengujian data pelangganlangkah selanjutnya dilakukan perkiraan dari tahun 2020 sampai 2025 pada PT. PLN rayon Juwana.Langkahnya sama dengan saat pengujian yaitudiambil dua tahun sebelum tahun prediksi untuk menghasilkan satu tahun berikutnya dengan parameter sama pada saat pengujian. Kemudian didapat hasil pada tabel 6 .

Tabel 7. Hasil Perkiraan Pelanggan Listrik Tahun 2020-2025

\begin{tabular}{|c|c|c|c|c|}
\hline TAHUN & RUMAH & TNDUSTRI & BISNIS & PUBLIR \\
\hline 2020 & 170965 & 259 & 7756 & 5824 \\
\hline 2021 & 177539 & 359 & 8266 & 6069 \\
\hline 2022 & 182759 & 397 & 9004 & 6831 \\
\hline 2023 & 189614 & 492 & 10004 & 7593 \\
\hline 2024 & 198378 & 603 & 11228 & 8954 \\
\hline 2025 & 211414 & 811 & 13487 & 11182 \\
\hline \multicolumn{5}{|c|}{ Pelanggan Listrik } \\
\hline \multicolumn{5}{|c|}{250000} \\
\hline \multirow{4}{*}{ 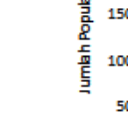 } & & & \\
\hline & & & & —Rumah Tangga \\
\hline & & & \multicolumn{2}{|c|}{ —industri } \\
\hline & & & \multicolumn{2}{|l|}{$\begin{array}{l}\text { - Bisnils } \\
\text { - Publik }\end{array}$} \\
\hline
\end{tabular}

Gambar 4.2 Grafik Perkiraan Tahun 2020 Sampai 2025

\subsection{Analisa Kenaikan Kebutuhan Listrik Rayon juwan}

4.2.1 Perkiraan Pelanggan Listrik RayonJuwana

\begin{tabular}{|c|c|c|c|c|c|}
\hline \multicolumn{6}{|c|}{$\begin{array}{l}\text { Pertumbuhan Perk } \\
: \text { Hasil Tahun Proyeksi }\end{array}$} \\
\hline Iasil Tahun & Sebelumn & & & & \\
\hline TAHUN & $\begin{array}{l}\text { RUMAH } \\
\text { TANGGA }\end{array}$ & INDUSTRI & BISNIS & PUBLIK & $\begin{array}{l}\text { RATA- } \\
\text { RATA }\end{array}$ \\
\hline 2020 & $0,10 \%$ & $1,21 \%$ & $1,11 \%$ & $1,13 \%$ & $0,89 \%$ \\
\hline 2021 & $1,03 \%$ & $1,38 \%$ & $1,06 \%$ & $1,04 \%$ & $1,13 \%$ \\
\hline 2022 & $1,02 \%$ & $1,10 \%$ & $1,08 \%$ & $1,12 \%$ & $1,08 \%$ \\
\hline 2023 & $1,03 \%$ & $1,24 \%$ & $1,11 \%$ & $1,11 \%$ & $1,12 \%$ \\
\hline 2024 & $1,04 \%$ & $1.22 \%$ & $1,12 \%$ & $1,17 \%$ & $1,14 \%$ \\
\hline 2025 & $1,06 \%$ & $1,34 \%$ & $1,20 \%$ & $1,24 \%$ & $1,21 \%$ \\
\hline
\end{tabular}

\subsubsection{Perkiraan energi Listrik Rayon Juwana}

Tabel 9. Pertumbuhan Perkiraan Energi Tahun 2020-2025

\begin{tabular}{|c|c|c|c|c|c|}
\hline TAHUN & $\begin{array}{c}\text { RUMAH } \\
\text { TANGGA }\end{array}$ & INDUSTR & BISNIS & PUBLIK & $\begin{array}{l}\text { RATA- } \\
\text { RATA }\end{array}$ \\
\hline 2020 & $1,11 \%$ & $1,18 \%$ & $1,02 \%$ & $1,17 \%$ & $1,12 \%$ \\
\hline 2021 & $1,09 \%$ & $1 \%$ & $1,28 \%$ & $1,34 \%$ & $1,18 \%$ \\
\hline 2022 & $1,25 \%$ & $1,24 \%$ & $1,01 \%$ & $1,25 \%$ & $1,19 \%$ \\
\hline 2023 & $1,19 \%$ & $1,04 \%$ & $1,51 \%$ & $1,56 \%$ & $1,33 \%$ \\
\hline 2024 & $1,47 \%$ & $1,35 \%$ & $1,06 \%$ & $1,57 \%$ & $1,36 \%$ \\
\hline 2025 & $1,60 \%$ & $1,32 \%$ & $2 \%$ & $1,8 \%$ & $1,68 \%$ \\
\hline
\end{tabular}

4.2.3 Perkiraan daya tersambung Rayon Juwana Tabel 10. Pertumbuhan Perkiraan daya tersambung Tahun 20202025

\begin{tabular}{|r|r|r|r|r|r|}
\hline TAHUN & $\begin{array}{r}\text { RUMAH } \\
\text { TANGGA }\end{array}$ & INDUSTR & BISNIS & PUBLIK & $\begin{array}{l}\text { RATA- } \\
\text { RATA }\end{array}$ \\
\hline 2020 & $1,19 \%$ & $1,32 \%$ & $1,26 \%$ & $1,42 \%$ & $1,3 \%$ \\
\hline 2021 & $1,14 \%$ & $1,24 \%$ & $1,47 \%$ & $1,48 \%$ & $1,33 \%$ \\
\hline 2022 & $1,63 \%$ & $1,57 \%$ & $1,56 \%$ & $1,52 \%$ & $1,57 \%$ \\
\hline 2023 & $1,47 \%$ & $1,51 \%$ & $1,38 \%$ & $1,22 \%$ & $1,4 \%$ \\
\hline 2024 & $1,1 \%$ & $1,02 \%$ & $1 \%$ & $1 \%$ & $1,03 \%$ \\
\hline 2025 & $1,05 \%$ & $1,1 \%$ & $1 \%$ & $1,03 \%$ & $1,06 \%$ \\
\hline
\end{tabular}




\subsection{Perkiraan Kebutuhan energi Listrik rayon}

\section{Juwana}

Pembangkit tenaga listrik wilayah Jawa Tengah dibawah kendali PT. PLN APB Jateng-DIYyang terhubung dengan sistem ketenagalistrikan Jawa- BaliMadura yang terdiri dari pembangkit sebagian besar thermal dan beberapa pembangkit hidro.

Berikut data total produksi energi yang dihasilkan oleh pembangkit Jawa Tengah.

Tabel 11. Energi Produksi dan Beban Puncak Pembangkit Jawa Tengah Tahun 2018-2019

\begin{tabular}{|r|r|r|}
\hline Tahun & $\begin{array}{c}\text { Energi Produksi } \\
\text { (MWh) }\end{array}$ & $\begin{array}{c}\text { Beban Puncak } \\
\text { (MW) }\end{array}$ \\
\hline 2018 & 313886 & 291 \\
\hline 2019 & 336734 & 289 \\
\hline
\end{tabular}

\subsubsection{Perkiraan Kebutuhan Energi Rayon Ju- wana Tahun 2020}

Energi Produksi $(2020)=(((P+e+d)) \times$ EP 2019) dengan :

$\mathrm{p}=$ rata rata pertumbuhan pelanggan 2020

$\mathrm{e}=$ rata rata pertumbuhan konsumsi energi 2020

$\mathrm{d}=$ rata rata pertumbuhan daya tersambung 2020

EP $2020=$ Energi Produksi tahun 2019

- Energi Produksi $(2020)=$

$$
(((0,89 \%+1,12 \%+1,3 \%)) \times 336734)
$$

3

$$
=371529 \mathrm{MWh}
$$

- Beban Puncak $(2020)=$

$$
(((0,89 \%+1,12 \%+1,3 \%)) \times 289)
$$

3

$$
=319 \mathrm{MW}
$$

Tabel 12. Perkiraan Kebutuhan Energi Rayon Juwana 2018-2025

\begin{tabular}{|r|r|r|}
\hline Tahun & $\begin{array}{c}\text { Energi Produksi } \\
\text { (MWh) }\end{array}$ & $\begin{array}{c}\text { Beban Puncak } \\
\text { (MW) }\end{array}$ \\
\hline 2018 & 313886 & 291 \\
\hline 2019 & 336734 & 289 \\
\hline 2020 & 371529 & 319 \\
\hline 2021 & 450788 & 387 \\
\hline 2022 & 577008 & 495 \\
\hline 2023 & 740493 & 635 \\
\hline 2024 & 871313 & 747 \\
\hline 2025 & 1147228 & 984 \\
\hline
\end{tabular}

\subsection{Kesimpulan}

\section{Penutup}

1. Perkiraan sektor jumlah pelanggan, jumlah energi, dan daya tersambung menggunakan jaringan saraf tiruan radial basis functionrata-rata sektor yang paling tinggi diduduki oleh rumah tangga dari ke empat sektor yang dianalisa, dan semua sektor mengalami kenaikan setiap tahunnya.
2. Hasil perkiraan kenaikan kebutuhan beban energi listrik tahun 2020 sampai 2025 rata- rata di empat sektor mengalami naik turun,pada tahun 2020 bernilai $1,10 \%, 2021$ bernilai $1,21 \%$, untuk tahun 2022 bernilai $1.27 \%, 2023$ bernilai 1,28\%, 2024 bernilai $1,17 \%$ dan 2025 bernilai $1,31 \%$.

3. Rata-rata pertumbuhan perkiraan pemakaian pelanggan listrik per tahun dari empat sektorpada 2020 bernilai $0,89 \%, 2021$ bernilai $1,13 \%, 2022$ bernilai $1,08 \%, 2023$ bernilai $1,12 \%, 2024$ bernilai $1,14 \%$, dan pada 2025 bernilai $1,21 \%$. untuk pemakaian energi listrik per tahun pada 2020 bernilai $1,12 \%, 2021$ bernilai $1,18 \%, 1,68 \%$.untuk pemakaian daya tersambung listrik per tahun pada 2020 bernilai 1,30\%,2021 bernilai 1,33\%, 2022 bernilai $1,57 \%, 2024$ bernilai $1,03 \%$ dan pada 2025 bernilai $1,06 \%$.

\subsection{Saran}

1. Untuk mendapatkan hasil perkiraan maksimal perlu mencoba berkali-kalidengan mengganti performa pelatihan jaringan syaraf tiruan $\mathrm{ra}$ dial basis function seperti pada performa spread, learning rate,epoch sehingga didapat hasil uji dengan keakuratan terbaik.

2. Pengambilan data yang terkait dengan penelitian disarankan untuk dilakukan pada awal melakukan penelitian.

3. Untuk mendapatka hasil perkiraan yang terbaik atau lebih akurat, sebaiknya melakukan pelatihan data minimal delapan tahun sebelum tahun perkiraan, agar pada saat melakukan perkiraan dapat hasil yang maksimal.

4. Berdasarkan hasil perkiraan, PT.PLN khususnya rayon Juwana sebagai perusahan penyedia energi listrik, sebaiknya melakukan perkiraan pemakaian dan kebutuhan energi listrik supaya pada tahun berikutnya dapat memenuhi kebutuhanpelanggan.

\section{DAFTAR PUSTAKa}

[1] Abdillah, 2020.rumus menghitung daya listrik dancontoh soal lengkap https://rumusrumus.com/rumus-daya- listrik di akses pada 5 agustus 2020

[2] Arief, Hariyanto. 2005. Jaringan Syaraf Tiruan danTeori Aplikasi Pemogramanya. Surabaya

[3] Ariwibowo,C, Trafo Distribusi pada JTM $20 \mathrm{kv}$ diPT. PLN (persero) UPJ_Data Kelistrikan PLN Tahun 2014, 2016 dan 2017

[4] Hasan Basri, Ir.,2003. Teknik Distribusi JaringanListrik Menengah Dan Tegangan Tinggi. Jakarta

[5] Hermawan, dan karnoto. 2008. Buku Manual Perencanaan Pengembangan sistem tenaga listrik. Univeritas diponegoro. Semarang 
[6] J. Siang, Jak. 2005. Dasar - Dasar Pengolahan Jaringan Syaraf Tiruan. Jakarta

[7] Puspitaningrum.2006. Struktur Jaringan Syaraf Tiruan Backpropagation dan RadialBasis Function. Jakarta

[8] Suhadi, dkk. 2008. Teknik Distribusi Tenaga ListrikJilid 1. Jakarta: Departemen Pendidikan Nasional.

[9] Sari, Dinar Atika. 2012. "Peramalan KebutuhanBeban Jangka Pendek Menggunakan Jaringan Syaraf Tiruan Backpropagation". Semarang: Universitas Diponegoro.

[10] Wisnu, arinanda. 2018. perkiraan konsumsi energilistrik di rayon Bangsri tahun 2018-2022 menggunakan metode Jaringan saraf tiruan (backpropagation)"

[11] Cahyanova.2013."Perkiraan Kebutuhan Energi Listrik Sistem Distribusi Tahun 2012-2017 Di PT.PLN (Persero) Rayon Batang Menggunakan Jaringan Syaraf Tiruan (JST)". 